o the incorporation of mental health services within primary health care.

A fair portion of this strategy has been implemented. For example:

O by 1995, 100 general practitioners had received training (with notable success), as had 60 paramedical staff

o psychiatrists now cover 36 health centres in Amman, and this programme has been extended to four other muhafazat (governorates)

o psychological counselling centres, staffed by social workers and psychology graduates, have been established in all the main schools in Jordan.

\section{Cultural issues}

Social stigma is quite strong in relation to psychiatric patients and treatments. Consequently, resort is often made to faith healers before or even after visiting a psychiatrist. There is great ignorance about psychiatry in all sectors of society: rich, poor, illiterate and educated. Stigma also affects the status of psychiatry among the other medical specialties. This has restricted progress in the delivery of psychiatric services.

\section{Sources}

Department of Statistics (2002) Population and Family Health Survey. Amman: Department of Statistics.

Ministry of Health (1988) Mental Health Strategy in Jordan. Report to the World Health Organization. Amman: Ministry of Health.

Shuriquie, N. (2003) Military psychiatry - a Jordanian experience. Psychiatric Bulletin, 27, 386-388.

Website

Jordan Medical Council: www.jmc.gov.jo

\title{
The mental health care system in Malta
}

\section{Susanna Galea ${ }^{1}$ and John Mifsud ${ }^{2}$}

${ }^{1}$ Clinical Lecturer and Specialist Registrar in Addictive Behaviour, Department of Mental Health, St George's Hospital Medical School, London, email sgalea@sghms.ac.uk; Member of the Royal College of Psychiatrists; Member of the Association of Maltese Specialists in Psychiatry

${ }^{2}$ Consultant Psychiatrist, Our Lady of Mount Carmel Psychiatric Hospital, Malta; Honorary Senior Lecturer, Department of Psychiatry, University of Malta, email psy@shadow.net.mt; Member of the Association of Maltese Specialists in Psychiatry

he Maltese Islands are located in the Mediterranean Sea and have a total area of $316 \mathrm{~km}^{2}$. They consist of three inhabited islands - Malta (the largest of the group), Gozo and Comino - and two uninhabited islands - Filfla and Cominotto. Malta is a democratic republic. Since its independence in 1964, Malta has played a more significant part in international relations. It became a member of the Commonwealth, the United $\mathrm{N}$ ations, the World Health $\mathrm{O}$ rganization and several other organisations. In May 2004, Malta also became a member of the European Union.

The organisation and delivery of mental health services, and access to them, are influenced by Malta's sociocultural specifics. Most ( $98 \%$ ) of the Maltese population is $C$ atholic and the Church plays an influential role in Maltese society. It contributes to the Maltese perception of mental illness and its aetiology and consequences, as well as to the nature of presentation and the utilisation of services. It also affects the community support network and rehabilitation. The geographical proximity of the populace and the predominance of the extended family also play a significant role in the perception, nature and progression of mental illness.

\section{Population}

The population of the Maltese Islands in 2002 was recorded at 394 000. Since 1974, the population has grown linearly and in 2001 the natural population growth was estimated at 2.5 per 1000 population (World H ealth 0 rganization, 2003). The total number of births in 2002 was 3805, giving a crude birth rate of 9.7 per 1000 population. In the same year, the total number of deaths was 3031, giving a crude death rate of 7.7 per 1000 population. The main causes of death among the Maltese population are non-communicable diseases, mainly circulatory disease and cancers. The life expectancy at birth in 2002 was 75.8 years for males and 80.5 years for females ( $N$ ational Statistics 0 ffice, 2003; Ministry of Health, 2004a).

\section{The organisation of health care}

The Maltese government provides a free national health service, for which the Minister of $\mathrm{H}$ ealth has overall responsibility. Residents receive comprehensive care, funded from general taxation (M inistry of Health, 2004b). The proportion of M alta's gross domestic product allocated to the health budget is $6.3 \%$. Residents are not obliged to have health insurance in order to be entitled to health
There is great ignorance about psychiatry in all sectors of society: rich, poor, illiterate and educated. Stigma also affects the status of psychiatry among the other medical specialties.
Most (98\%) of the Maltese population is Catholic and the Church plays an

influential role in Maltese society. It contributes to the Maltese perception of mental illness and its aetiology and consequences, as well as to the nature of presentation and the utilisation of services. 
services, and those determined by means-testing to have a 'low income' and those suffering from chronic conditions (e.g. schizophrenia) are entitled to free drug treatment. Means-tested social assistance benefits are offered to some of those who have a mental health disorder, including those with severe learning disabilities, schizophrenia, certain neurological conditions (e.g. epilepsy) and substance misuse (World Health O rganization, 2002).

Private health services run alongside the national health service. Private general practitioners as well as specialist practitioners offer community health services. There are three private hospitals on Malta.

\section{Mental health resources}

The provision of mental health care falls under the same organisational system as general health. $0 \mathrm{f}$ the overall health care budget, $9 \%$ is allocated to mental health (World H ealth O rganization, 2002). Most of the services are offered as part of the national health service, although private services also offer community specialist care. Two non-governmental organisations, the Friends of Attard Hospital Society and the Richmond Foundation, run alongside the public and private provision.

The Ministry of $\mathrm{H}$ ealth gives its mission statement as follows: 'to promote and provide for the health care needs of the Maltese people and to deliver appropriate services' (M inistry of Health, 2004c). The mental health policy aims to promote a healthy environment within Maltese society, and to empower individuals to cope better with mental health issues. The policy's objectives are to deliver a wide range of services, and to facilitate advocacy, promotion, prevention, treatment and rehabilitation (World Health O rganization, 2002).

The public mental health service falls under eight consultant-led firms. In-patient facilities are offered at two sites: St Luke's H ospital, which has a short-stay psychiatric unit (with 11 beds); and Mount C armel H ospital, which has beds for acute, rehabilitation and long-stay patients, as well as beds specifically for older people, children and adolescents and people with learning disabilities, and a forensic ward. Mount Carmel Hospital provides for 520 beds in total, accounting for 143.3 beds per 100000 population (World Health 0 rganization, 2003). When compared with other European countries, Malta has one of the highest numbers of psychiatric beds per 1000 population (World Health O rganization, 2003). However, when considering the provision for acute admissions, each consultant firm is entitled to only four beds (two for men and two for women), which makes acute in-patient care difficult to access.

M ount $\mathrm{C}$ armel H ospital also offers para-clinical services, electroconvulsive therapy and a consultation- liaison service to other government hospitals. Community care facilities are offered at other sites and include:

- psychiatric out-patient facilities at St Luke's H ospital and Gozo Psychiatric Hospital, as well as within community-based health centres

O a child guidance clinic

o a clinical psychology service o electroconvulsive therapy at the St Luke's site

o occupational therapy day services.

0 ther community care facilities include day centres, sheltered homes, long-stay hostels, respite centres and independent living, offered by both the governmental and non-governmental organisations, including the church. Community care, principally in the form of out-patient follow-up, is also offered by the private sector, by a psychiatrist or a general physician. M ount $\mathrm{C}$ armel $\mathrm{H}$ ospital coordinates the overall mental health provision. $\mathrm{N}$ ongovernmental organisations' main roles are advocacy, promotion and rehabilitation for individuals with mental illness and their families.

The eight consultant-led firms operate within all the mental health facilities; some teams offer some specialist care, depending upon the relevant consultant's training and special interests. For example, the team led by the consultant author offers specialist provision for eating disorders and sexual disorders, as well as general psychiatric provision. Fifty psychiatric nurses, eight generic occupational therapists, six generic social workers and four psychologists work alongside the eight consultants, with the aim of implementing a multi-disciplinary approach. In-patient and community care facilities also aim to function through holistic approaches, according to individual needs, which may involve engaging the whole family in treatment. However, partly because of the limited human resources, in-patient care still operates in a largely custodial manner. Similarly, a multi-disciplinary approach within community care facilities is limited, with provision mainly consisting of follow-up by a physician.

Provision for substance misuse falls under the Ministry of Family and Social Solidarity. Most of the substance misuse services are provided by a government-funded auto nomous agency, the $\mathrm{N}$ ational Agency against $\mathrm{D}$ rug and Alcohol Abuse (Sedqa). The objective of the Agency is:

'[to] plan and recommend developments and updates of the National Policy in the field of drug and alcohol abuse and to provide services in health promotion, prevention, treatment and rehabilitation to persons with drug and/or alcohol problems and to their families so as to help them live a stable life and to integrate better [into] society' (Sedqa, 1994).

The services principally employ a multi-disciplinary approach, and provide a range of treatment modalities, including out-patient and in-patient detoxification, community-based one-to-one as well as group psychoso cial interventions, family therapy facilities and longer-term residential rehabilitation facilities. 0 ther community-based provision includes prevention programmes and a parental skills programme (Bell, 1997; Bugeja, 2000). Acute provision for substance misuse, however, falls under the Department of Psychiatry within the main psychiatric hospital. A non-governmental organisation, Caritas, works alongside the $\mathrm{N}$ ational Agency; its main roles are prevention and community-based rehabilitation. The D epartment of Psychiatry also provides for psychiatric care within the criminal justice system. 


\section{Training}

Basic undergraduate training in the field of psychiatry forms part of the MD curriculum. This is in the form of formal lectures as well as clinical placement within the various mental health facilities (U niversity of Malta, 2003). 0 pportunities for postgraduate training in psychiatry include clinical placements at the levels of house officer (four posts) and senior house officer (seven posts), under the supervision of the consultant psychiatrists. Formal training in psychiatry leading on to full qualification as a psychiatrist is not provided in Malta and hence doctors must acquire formal training abroad.

The $N$ ational Agency against D rug and Alcohol Abuse provides basic training in substance misuse for those involved in service provision. It also offers a 'Voluntary Action Training Programme' for leading figures in the community, to facilitate a preventive approach with youths (Bugeja, 2000).

Membership of the Association of Maltese Specialists in Psychiatry provides the specialist registration of psychiatrists. Following recent developments, all psychiatrists will have recognition and registration of their specialty only if they are approved by the Association. There is no specialist registration for the other disciplines.

\section{Research activities}

M ental health research activities are conducted by each consultant on some practical aspect of psychiatric care. The aim of such research is the improvement of psychiatric care and its delivery. Research projects are usually conducted over a 12-month period and are funded in part by the Merit Award Scheme. 0 ther research activities are conducted by undergraduate and postgraduate students at the U niversity of Malta.

\section{Conclusion}

Mental health services in Malta are tailored to the sociocultural needs of the population. Provision of care tends to be personalised and holistic, with specialist care being an integral part of general psychiatric care. The national health service and services provided by both non-governmental organisations and the private sector function together, which allows individuals to choose their preferred option of care, and it is easy to switch between each mode of provision. The number of beds available for acute admissions is insufficient for the population, despite the relatively high number of psychiatric beds per 100000 population. This is likely to be a consequence of the custodial care approach employed and of ineffective community care. Although services have actively been trying to move away from institutionalisation to a more community-based setting, the limited number of fully qualified mental health professionals makes this move difficult. Investment in and upgrading of training and research among all disciplines would provide the basis for a more modern, community-based, multi-disciplinary approach to the delivery of mental health care.

\section{References}

Bell, A. (ed.) (1997) Sedqa Annual Report. Malta: Union Print Company.

Bugeja, S. (2000) A profile of Sedqa - the National Agency Against Drug and Alcohol Abuse, Malta. Substance $M$ isuse Bulletin, 13, 6 .

Ministry of Health (2004a) The Health of the Maltese Nation. Available at www.gov.mt. Last accessed 27 April 2004.

Ministry of Health (2004b) The Health Care System in Malta. Available at www.gov.mt. Last accessed 27 April 2004.

Ministry of Health (2004c) The Ministry. Available at www.gov.mt. Last accessed 27 April 2004.

N ational Statistics O ffice (2003) Demographic Review 2002. Valletta: N ational Statistics 0 ffice.

Sedqa (1994) Sedqa Mission Statement. Available at www.sedqa.org.mt. Last accessed 27 April 2004.

University of Malta (2003) Psychiatry Lecture Programme, MD Course Vth Year, Faculty of Medicine and Surgery. Available at http://home.um.edu.mt/med-surg/courses/vthyear/ psychiatryl.html. Last accessed 27 April 2004.

World Health Organization (2002) Atlas: Country Profiles on Mental Health Resources. Project Atlas: Country Profile: Malta. Geneva: WHO.

World Health Organization (2003) Atlas of Health in Europe. Geneva: WHO.
Although services have actively been

trying to move away from

institutionalisation

to a more

community-based setting, the limited

number of fully

qualified mental

health

professionals

makes this move difficult.

\section{Formal training in psychiatry leading on to full}

qualification as a psychiatrist is not provided in Malta and hence doctors must acquire

formal training abroad.

\title{
The mental health policies of Trinidad and Tobago
}

\author{
Hari D. Maharajhํㅡ and Akleema Ali²
}

${ }^{1}$ Senior Lecturer, Faculty of Medical Sciences, Department of Psychiatry, University of the West Indies, Mt Hope, Trinidad, West Indies, email drharim@carib-link.net

${ }^{2}$ PhD Student, Faculty of Social Sciences, Department of Behavioural Sciences, University of the West Indies, St Augustine, Trinidad, West Indies

he Republic of Trinidad and Tobago is the most southerly of the Caribbean island states. Trinidad is just $14 \mathrm{~km}$ from the coast of Venezuela. Trinidad covers an area of $4828 \mathrm{~km}^{2}$ while Tobago, the sister isle, has an area of 300 $\mathrm{km}^{2}$. The total population is approximately 1.3 million; $40.3 \%$ of the population is of East Indian descent, $39.6 \%$ of African descent, $18.4 \%$ mixed 